\title{
Contribution of early nutrition on the development of malnutrition and allergic diseases in the first year of life: a study protocol for the Mother and Infant Cohort Study (MICOS)
}

Fui Chee Woon ${ }^{1}$, Yit Siew Chin ${ }^{1 *}$ (D), Intan Hakimah Ismail ${ }^{2}$, Yoke Mun Chan ${ }^{1,3}$, Marijka Batterham ${ }^{4}$, Amir Hamzah Abdul Latiff ${ }^{5}$, Wan Ying Gan ${ }^{1}$ and Geeta Appannah'

\begin{abstract}
Background: Nutrition and environmental factors are essential for the education of the neonatal immune system. Epidemiological evidence has shown that malnutrition and allergic diseases that occur during early childhood share similar protective and risk factors. This paper describes the protocol of the Mother and Infant Cohort Study (MICOS), which aims to determine the contribution of early nutrition to the development of malnutrition and allergic diseases in infants' first year of life.

Methods: MICOS is a prospective cohort study conducted at selected government health clinics in two states, namely Selangor and Wilayah Persekutuan Kuala Lumpur, Malaysia. Women in their third trimester of pregnancy are recruited into the study and their infants will be followed-up at 3, 6, and 12 months of age. Information on prenatal factors including socio-demographic characteristics, obstetric history, pre-pregnancy body mass index, gestational weight gain, smoking, family history of allergic diseases, maternal dietary intake and sunlight exposure during pregnancy are obtained through face-to-face interviews. Postnatal factors including dietary intake, sun exposure, and anthropometric measurements of the mothers, as well as feeding practices, dietary intake, anthropometric measurements, and development of allergic diseases of the infants are assessed at each follow-up. Blood samples are collected from the mothers in the third trimester to determine 25-hydroxyvitamin D levels as well as from the infants at age 12 months to determine atopic sensitisation.

Discussion: The concept of developmental origins of health and disease (DOHaD) which emphasises on the role of early life environments in shaping future health and disease susceptibility in adulthood has gained a huge interest in recent years. The $\mathrm{DOHaD}$ paradigm has influenced many fields of research including malnutrition and allergic diseases. While findings from the developed countries remain controversial, such studies are scarce in developing countries including Malaysia. The present study will determine the cause and effect relationship between early nutrition and the development of malnutrition and allergic diseases in infants' first year of life.
\end{abstract}

Keywords: MICOS, Infant, Early nutrition, Allergic diseases, Malnutrition

\footnotetext{
*Correspondence: chinys@upm.edu.my

'Department of Nutrition and Dietetics, Faculty of Medicine and Health

Sciences, Universiti Putra Malaysia, 43400 UPM Serdang, Selangor, Malaysia

Full list of author information is available at the end of the article
}

(c) The Author(s). 2018 Open Access This article is distributed under the terms of the Creative Commons Attribution 4.0 International License (http://creativecommons.org/licenses/by/4.0/), which permits unrestricted use, distribution, and

reproduction in any medium, provided you give appropriate credit to the original author(s) and the source, provide a link to the Creative Commons license, and indicate if changes were made. The Creative Commons Public Domain Dedication waiver (http://creativecommons.org/publicdomain/zero/1.0/) applies to the data made available in this article, unless otherwise stated. 


\section{Background}

Inadequate intake of energy and nutrients may lead to malnutrition in the form of muscle wasting, stunted growth, and being underweight while excessive intake may lead to being overweight and obese [1]. Both forms of malnutrition occur among Malaysians. According to the National Health and Morbidity Survey (NHMS) 2015 Malaysia, approximately $17.7 \%$ of children below five years of age were stunted, $12.4 \%$ were underweight, $8.0 \%$ were wasted, and $7.6 \%$ were overweight [2]. Childhood malnutrition is linked to a high risk of mortality, lower levels of cognitive development, an increased susceptibility to childhood infectious diseases and lower levels of labor productivity in adulthood [3-7].

Allergy is an abnormal over-reaction or hypersensitivity reaction of the body caused by specific immunologic mechanisms which occur after an exposure to substances that are normally harmless to the human body [8]. Food allergy and eczema are the first manifestations of allergy, which usually appear during the first two years of life. Although many children outgrow their allergies, some still continue to have them. Additionally, some allergic disorders can change and progress to asthma and allergic rhinitis in later childhood. This phenomenon is known as the "atopic march" $[9,10]$. The International Study of Asthma and Allergies in Childhood (ISAAC) reported that $12.6 \%$ of children (6-7 years old) in Malaysia have eczema, 5.8\% have asthma, and $4.8 \%$ have allergic rhinitis [11]. Childhood allergies could lead to inappropriate diet elimination when parents are incorrectly advised and thus malnutrition, which will affect the quality of life of the patients as well as their families [12-14].

Malnutrition and allergic diseases are growing public health problems worldwide and are common diseases encountered during the first two years of life [10, 15]. As recent research demonstrated that nutrition is an essential prerequisite for the functionality of the immune system, both malnutrition and allergic diseases during childhood may have negative health consequences that persist into adulthood [10, 16]. Previous studies showed a significant association between allergic diseases and malnutrition [12, 17-22]. For example, food allergies can affect the growth and nutritional status of children with eczema. Therefore, there is a need to understand the role of early nutrition in preventing the first manifestation or progression of malnutrition and allergic diseases.

There is a growing body of evidence from research demonstrating that intrauterine exposures and early postnatal environment play a crucial role in determining the health and risk of disease later in life [23-25]. In addition, evidence from research revealed that early nutrition and lifestyle factors have long-lasting programming effects on the risk of later developing associated non-communicable diseases. Insults or stimuli that occur during the critical period, from pregnancy to early infancy, can trigger adaptations that lead to permanent changes in the structure and function of an organism, known as "programming" [26]. Early nutrition has been identified as one of the most important key players in programming; and thus, the right nutrition during the critical period is crucial to ensure proper growth and good health [25, 27].

The concept of early life nutrition refers to the maternal diet during pregnancy and lactation, as well as child feeding practices (breastfeeding and complementary feeding) [28]. Maternal nutrient requirements during pregnancy and lactation are increased in order to support fetal growth and production of breast milk [29]. During pregnancy, the supply of nutrients to the fetus is dependent on what mothers eat and the effectiveness of the placenta in transporting these nutrients to the fetus. A fetus may become undernourished when the nutrient supply does not meet its demand, thus resulting in fetal growth restriction, which is a major determinant of stunted linear growth and subsequent obesity in childhood [30]. On the other hand, maternal diet during lactation could influence her breast milk composition. Breastfeeding may protect infants against rapid weight gain and later obesity, which is possibly attributed to the bioactive components in breast milk that regulate an infant's appetite, metabolism, weight gain, and adiposity [31].

There are certain food items in a mother's diet during pregnancy and lactation such as fish and shellfish, peanut, and milk, which are potential food allergens, and could influence the risk of allergy among infants through in-utero allergen exposure transplacentally or transamniotically [32-34]. In-utero allergen exposure could influence the fetal immune response to shift towards development of tolerance or development of an allergic disease [34, 35]. Maternal dietary allergen exposure during lactation could influence the risk of allergy among infants through food allergens that are passed through human milk [36] which might promote tolerance in a newborn and subsequently reduce the risk of allergic diseases [18, 37]. Breast milk consists of an abundance of immunomodulatory components such as IgA, cytokines, chemokines, growth factors, and essential fatty acids which are essential to promote the development of the infant immune system [38-40]. A shorter duration of breastfeeding has been shown to be associated with an increased risk of asthma and allergic diseases in infants [41, 42]. Meanwhile, early introduction to allergenic food might decrease the risk of allergic diseases by promoting tolerance in infants $[43,44]$. Apart from dietary allergen exposure, maternal intake of specific nutrients such as vitamin D and polyunsaturated fatty acids (PUFA) during pregnancy may also affect the risk of development of allergic diseases in offspring. Several studies from Western countries found that high maternal 
vitamin D and total PUFA intake during pregnancy were associated with a decreased risk of allergic diseases in children [45-48].

Although there are many prospective cohort studies on the association between early life nutrition and childhood malnutrition or allergy, the majority of these works were conducted in developed countries and some of the outcomes remain controversial [17-20, 22, 46, 49]. In addition, these studies focused on a single outcome, even though both allergy and malnutrition share a similar risk factor, which is early life nutrition. The Mother and Infant Cohort Study (MICOS) is therefore designed to determine the association between early life nutrition and the development of malnutrition and allergy in infants. The prospective cohort study design of MICOS involves an assessment of pre- and postnatal dietary exposures at multiple time points. Additionally, the environmental factors, family history, and maternal obstetric history are assessed to provide a comprehensive assessment of factors related to the development of childhood malnutrition and allergy. The prevalence of allergic diseases and malnutrition will be assessed and the scientific evidence on the cause and effect relationship between early nutrition and the development of allergic diseases and malnutrition in infants will be investigated. The aim of this paper is to describe the rationale and methodology of MICOS in addressing the need to investigate the association of early nutrition with malnutrition and allergy.

\section{Aim of the study}

The present study aims to determine the contribution of early nutrition on the development of malnutrition and allergic diseases in infants at 12 months of age. The specific research questions to be answered by this study are as follows:

- What is the incidence of malnutrition in infants at 12 months of age?

- What is the incidence of allergic diseases in infants at 12 months of age?

- Is early nutrition associated with the development of malnutrition and allergic diseases in infants at 12 months of age?

- Is there any association between development of allergic diseases and malnutrition in infants at 12 months of age?

\section{Methods/design}

\section{Study design and setting}

MICOS is a prospective cohort study involving pregnant women in their third trimester of pregnancy ( $\geq 28$ weeks of gestation) who are attending six randomly selected Maternal and Child Health clinics in the state of Selangor and the city of Kuala Lumpur, Malaysia. The Maternal and Child Health $(\mathrm{MCH})$ clinics are the primary source providing antenatal and postnatal care to pregnant women. In the present study, pregnant women are enrolled at $\geq 28$ weeks of gestation and are followed-up prospectively at 3, 6, and 12 months postpartum together with their infants (Fig. 1).

\section{Recruitment of respondents}

The respondents are selected using a cluster sampling method. A list of government health clinics in Selangor and Kuala Lumpur was obtained from the Selangor and Kuala Lumpur Health Departments. Six health clinics that met the inclusion criteria (government-funded and have a $\mathrm{MCH}$ clinic) were randomly selected. Pregnant women who are Malaysian, aged 18 years and above, gestational age $\geq 28$ weeks, attending the selected government health clinics for antenatal check-up, and are planning to have postnatal check-up for at least one year at the same selected government health clinics are eligible to participate in this study. Women will be excluded if they are diagnosed with an immune deficiency, have a multiple pregnancy, have a preterm delivery before 37 weeks, or if their baby is born with congenital abnormalities. The objective of the study and the study procedure will be explained to the potential respondents at the clinic waiting area whilst they are waiting their turn for the antenatal check-up. Written informed consent for the respondents and their baby are obtained from the respondents who agree to participate in the study.

\section{Sample size calculation}

Sample size was calculated using the formula for cohort study [50] with $95 \%$ power and 5\% significance level. A total of 371 pregnant women is required for the study. Taking into account for a design effect of 1.119 [51] and a possible attrition rate of $28.5 \%$ [52], the sample size is increased to 533 pregnant women.

\section{Data collection}

Recruitment of respondents began in November 2016 and is currently on-going. Respondents are followed over time and the details of the variables assessed at each assessment point in this study are shown in Table 1.

\section{Instrumentations}

\section{Maternal questionnaires}

At the first encounter, information is gathered from women who are in their third trimester of pregnancy by a face-to-face interview. The information gathered includes socio-demographic characteristics (including age, ethnicity, marital status, educational level, occupation, and monthly household income), obstetrical history, smoking during pregnancy, medication use, and family history of allergic diseases. Body weight and height of the pregnant women before and during pregnancy are extracted from 


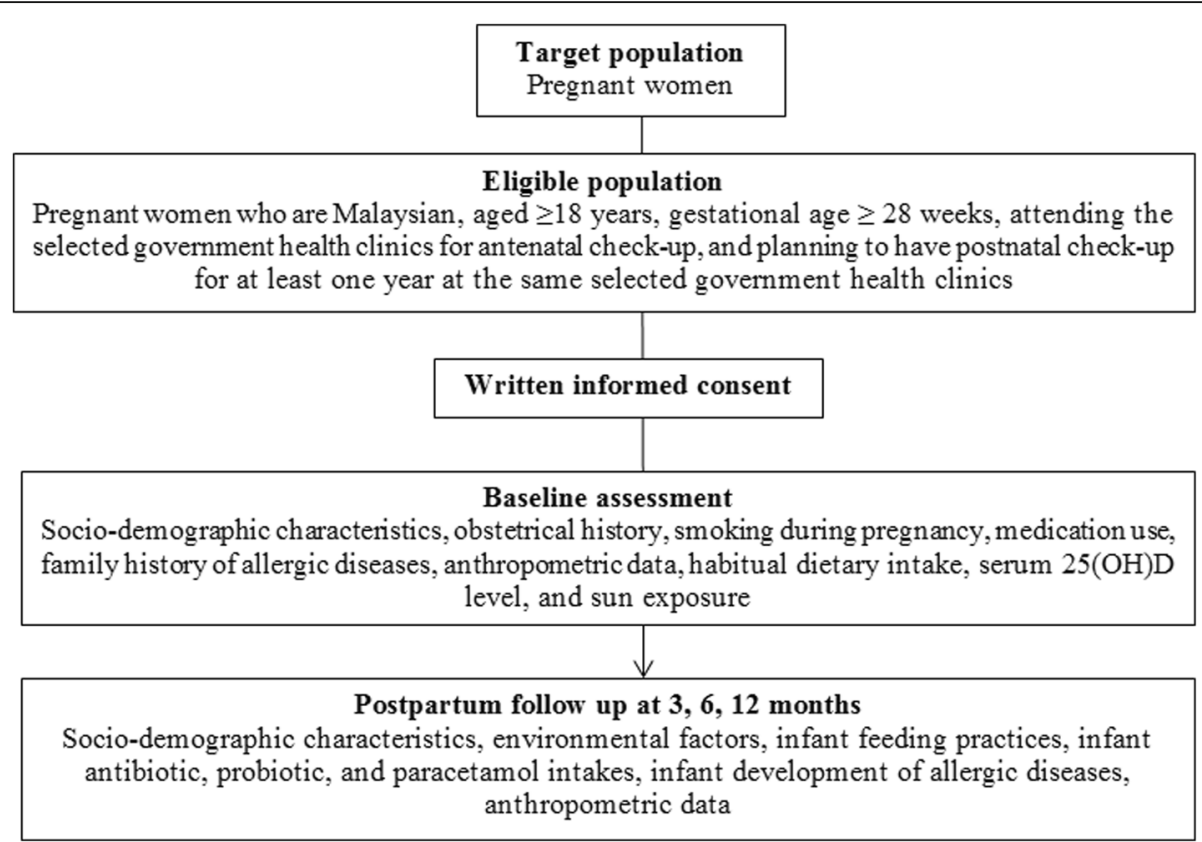

Fig. 1 Flow chart of the cohort study MICOS

their medical records, while body weight after delivery is measured at 3, 6, and 12 months. The measurements are recorded to the nearest $0.1 \mathrm{~kg}$ for weight and $0.1 \mathrm{~cm}$ for length, respectively. Pre-pregnancy Body Mass Index (BMI) is calculated by the weight in kilograms divided by the height in meters squared $(\mathrm{kg} / \mathrm{m} 2)$. Pre-pregnancy body weight status is classified into four categories based on the Institute of Medicine (IOM) Classification [53]. Total gestational weight gain (GWG) is calculated as the difference between the final recorded body weight at the last prenatal visit and the pre-pregnancy weight recorded at the first prenatal visit in the selected health clinics. The second and third trimesters mean weekly weight gain is estimated through the difference between the first and last weight recorded in the trimester divided by the number of weeks between the two observations. The maternal GWG is then categorised as inadequate, adequate, or excessive compared to the IOM [53] recommended weight gain based on their pre-pregnancy BMI group. Postpartum weight retention is calculated as the difference between the measured weight at 3,6 , and 12 months postpartum and pre-pregnancy weight, respectively.

\section{Maternal habitual dietary intake}

Maternal habitual dietary intake at the third trimester of pregnancy is assessed using a semi-quantitative food frequency questionnaire (FFQ), adapted from the Malaysian Adult Nutrition Survey (MANS) [54] and vitamin D FFQ [55]. Mothers are followed-up prospectively at 3, 6, and 12 months postpartum through face-to-face interviews. The serving size of the food consumed is estimated by using household measurements. The amount of food intake per day is calculated according to this formula: frequency of intake per day $x$ serving size $x$ total number of servings $x$ weight of food in one serving [56]. Data obtained will then be entered into the Nutritionist Pro $^{\mathrm{Tm}}$ Diet Analysis software to obtain the energy and nutrient intake of the women.

\section{Maternal vitamin D status}

A peripheral venous blood sample $(2 \mathrm{ml})$ is obtained from the women during their 3rd trimester of pregnancy by the nurses via venepuncture at the antecubital area to assess for vitamin D status. The ADVIA Centaur Vitamin D Total assay is used to determine maternal serum 25 hydroxy-vitamin D (25(OH)D) level. Maternal serum $25(\mathrm{OH}) \mathrm{D}$ level is then classified into vitamin D deficiency $(<30 \mathrm{nmol} / \mathrm{L})$, vitamin D insufficiency $(30-<50 \mathrm{nmol} / \mathrm{L})$ or vitamin D sufficient ( $\geq 50 \mathrm{nmol} / \mathrm{L})$ [57].

\section{Maternal sun exposure}

Maternal exposure to direct sunlight during the third trimester of pregnancy is determined using a Seven-day Sun Exposure Record [58] and followed-up prospectively at 3,6 , and 12 months postpartum. Women are required to record the time they spent outdoors, type of clothing worn, sunscreen use, and the nature of outdoor activities during the previous week from $7 \mathrm{am}$ to $7 \mathrm{pm}$. Body surface area (BSA) exposed is estimated by referring to the guidelines of clothing key [58]. Sun exposure index (SEI) is calculated by multiplying the amount of time spent outdoors with BSA exposed [58]. A higher SEI indicates a higher exposure to sunlight. 
Table 1 Summary of data collection and timeline (Under section: Data collection - page 10)

\begin{tabular}{|c|c|c|c|c|}
\hline \multirow[t]{2}{*}{ Variables } & \multirow{2}{*}{$\begin{array}{l}\text { Prenatal } \\
\text { 3rd trimester }\end{array}$} & \multicolumn{3}{|l|}{ Postnatal } \\
\hline & & 3 months & 6 months & 12 months \\
\hline \multicolumn{5}{|l|}{ Mothers } \\
\hline Age & $\sqrt{ }$ & & & \\
\hline Ethnicity & $\sqrt{ }$ & & & \\
\hline Educational level & $\sqrt{ }$ & & & \\
\hline Occupation & $\sqrt{ }$ & & & \\
\hline Monthly household income & $\sqrt{ }$ & & & \\
\hline Obstetric history & $\sqrt{ }$ & & & \\
\hline Pre-pregnancy body weight and height & $\sqrt{ }$ & & & \\
\hline Body weight during pregnancy & $\sqrt{ }$ & & & \\
\hline Body weight after delivery & & $\sqrt{ }$ & $\sqrt{ }$ & $\sqrt{ }$ \\
\hline Smoking during pregnancy & $\sqrt{ }$ & & & \\
\hline Habitual dietary intake & $\sqrt{ }$ & $\sqrt{ }$ & $\sqrt{ }$ & $\sqrt{ }$ \\
\hline Sun exposure & $\sqrt{ }$ & $\sqrt{ }$ & $\sqrt{ }$ & $\sqrt{ }$ \\
\hline Serum 25(OH)D level & $\sqrt{ }$ & & & \\
\hline \multicolumn{5}{|l|}{ Infants } \\
\hline Sex & & $\sqrt{ }$ & & \\
\hline Mode of delivery & & $\sqrt{ }$ & & \\
\hline Body weight, length, head circumferences & & $\sqrt{ }$ & $\sqrt{ }$ & $\sqrt{ }$ \\
\hline Family history of allergic diseases & $\sqrt{ }$ & & & \\
\hline Pet ownership & & $\sqrt{ }$ & $\sqrt{ }$ & $\sqrt{ }$ \\
\hline Day care attendance & & $\sqrt{ }$ & $\sqrt{ }$ & $\sqrt{ }$ \\
\hline Number of siblings & & $\sqrt{ }$ & & \\
\hline Environmental tobacco smoke exposure & & $\sqrt{ }$ & $\sqrt{ }$ & $\sqrt{ }$ \\
\hline Infant feeding practices & & $\sqrt{ }$ & $\sqrt{ }$ & $\sqrt{ }$ \\
\hline Antibiotic, probiotic, and paracetamol intakes & & $\sqrt{ }$ & $\sqrt{ }$ & $\sqrt{ }$ \\
\hline Development of allergic diseases & & $\sqrt{ }$ & $\sqrt{ }$ & $\sqrt{ }$ \\
\hline Atopic sensitization & & & & $\sqrt{ }$ \\
\hline
\end{tabular}

\section{Infant questionnaires}

Infant's sex and mode of delivery are extracted from their medical records during the follow up visit of the infants at 3 months. Environmental factors including pet ownership, daycare attendance, number of siblings, and environmental tobacco smoke exposure among the infants are obtained from their mothers through face-to-face interviews using The International Study of Asthma and Allergies in Childhood Questionnaires (ISAAC) Phase III Environmental Questionnaire [59] at 3, 6 and 12 months postpartum. Infant's weight, recumbent length, and head circumference data from birth to 12 months are extracted from their medical records. The anthropometric data at each age month is then converted to z-scores (length-for-age z-scores (LAZ), weight-for-age z-scores (WAZ), weight-for-length z-scores (WLZ), BMI-for-age Z-scores (BMIZ), and head circumference $\mathrm{z}$-scores (HCZ)) by using the WHO Reference 2007 SPSS macro package [60]. Infants nutritional status is defined as stunting ( $\mathrm{LAZ}<-2 \mathrm{SD})$, underweight (WAZ $<-2 \mathrm{SD}$ ), wasting (WLZ $<-2 \mathrm{SD}$ ), overweight (BMIZ $>+1 \mathrm{SD}$ ), obese $(\mathrm{BMIZ}>+2 \mathrm{SD})$, and microcephaly $(\mathrm{HCZ}<-2 \mathrm{SD})$ respectively, based on the WHO Child Growth Standards [60].

\section{Infant feeding practices}

Mothers are interviewed for infant feeding practices at 3, 6, and 12 months postpartum using the Infant and Young Child Feeding Questionnaire adapted from the Malaysian Third National Health and Morbidity Survey (NHMS III) [61] and are based on the indicators for infant and young child feeding (IYCF) suggested by WHO [62]. The seven core indicators include early initiation of breastfeeding, exclusive breastfeeding, continued breastfeeding, introduction of solid, semi-solid or soft foods, minimum dietary diversity, minimum meal frequency, and minimum acceptable diet, while the seven optional indicators include children never breastfed, continued breastfeeding, age-appropriate 
breastfeeding, predominant breastfeeding, duration of breastfeeding, bottle feeding, and milk feeding frequency for non-breastfed children.

\section{Infant antibiotic, probiotic, and paracetamol intakes}

Antibiotic, probiotic, and paracetamol intake of the infants at 3, 6, and 12 months are assessed by asking the mother: "Has your child ever consumed any antibiotic, probiotic, or paracetamol in the past three months?" and "If YES, how often in the past three months did your child consume it and how much did your child consume each time?"

\section{Infant development of allergic diseases Eczema}

Mothers are interviewed for the presence of eczema in infants at 3, 6, and 12 months based on five questions of the UK Working Party's Diagnostic Criteria for Atopic Dermatitis [63] with response options "yes" or "no". Eczema in infants is identified by the presence of an itchy skin condition plus two or more of the following; (i) history of involvement of skin creases such as folds of elbows, behind the knees, fronts of ankles, cheeks, or around the neck; (ii) a history of atopic disease in a first-degree relative; (iii) a history of a general dry skin; and (iv) visible flexural eczema.

\section{Food allergy}

Food allergy in infants at 3, 6, and 12 months are assessed by asking the mothers: "Has your child ever had a skin rash and sickness within two hours of eating some food?" and "Did these symptoms repeat each time the same food was consumed?" [64]. If positive answers are given to both of these questions, the mothers are required to select the type of food their children consumed that resulted in those symptoms. Options to select from include egg, peanut, tree nut, milk, shellfish, fish, wheat, and soy.

\section{Asthma}

The Asthma Predictive Index (API) [65] is used to determine the likelihood of infants who may develop asthma at 3, 6, and 12 months. A 'positive' API involves the presence of recurrent episodes of wheezing (more than three episodes per year) and one of two major criteria: (1) Asthma in a parent or (2) Eczema in infant; or two minor criteria: (1) Allergic rhinitis in infant and (2) Wheezing apart from colds in infant.

\section{Rhinitis}

Rhinitis in infants at 3, 6, and 12 months is assessed by the ISAAC questionnaire [66]. An infant is labelled to have rhinitis if the mothers report that the infant had a runny nose or sneezing episodes with no evidence of cold or flu.

\section{Infant atopic sensitization}

Peripheral venous blood samples are obtained from the infants via venepuncture at age 12 months. Approximately 1-2 $\mathrm{mL}$ of blood is collected by the medical assistants into 5-ml plain tubes. Serum samples are analyzed by using the OPTIGEN Allergen Specific Immunoglobulin E (IgE) Assay (Hitachi Chemical Diagnostics Inc., Japan) which enables the simultaneous determination of the infants' total IgE and specific IgE levels to a total of 35 food and inhalant allergens (egg yolk, egg white, soybean, peanut, milk, clam, crab, shrimp, cod fish, tuna, salmon, rice, wheat, banana, orange, sesame seed, chocolate, chicken, beef, mucor, timothy grass, bermuda glass, Alternaria, Aspergillus, Candida, Cladosporium, Penicillium, dog dander, cat dander, cockroach mix, housedust, Mite Farinae, Mie Pteronyssinus, Blomis Tropicalis, and latex). The results obtained from the test in net luminescence units (LU), are classified into class 0 (0$26 \mathrm{LU})$, class 1 (27-65 IU), class 2 (66-142 LU), class 3 (143-242 LU) and class 4 (> 243 LU) using the Chemiluminescent Assay (CLA) Class Allergy Scoring System (Hitachi Chemical Diagnostics Inc., Japan). Class $\geq 1$ is interpreted as positive, indicating that the infants are sensitised to a specific food or aero-allergens.

\section{Data analysis}

The IBM SPSS Statistics 24 software (SPSS Inc., Chicago, IL, USA) will be used to analyse the data. Descriptive statistics and univariate analysis will be performed to describe the data. Hierarchical linear regression analysis with confounders are forcibly entered to examine the association between various exposure variables and the longitudinal outcomes. Data will be presented as relative risk (RR) with 95\% confidence interval. Kaplan-Meier test and Cox regression analysis will be performed to analyse the time-to-event data and hazard ratios (HR) with a 95\% confidence interval will be reported.

\section{Discussion}

About $60 \%$ of allergies appear during the first year of life [10]. The "hygiene hypothesis" originally proposed by Strachan [67] suggests that environmental influences such as decreased or absence of microbial exposures in early life have an adverse effect on the development of the immune system, which may lead to the development of allergic diseases. The concept of early environmental influences on later disease also draws on the increasing interest in fetal programming, known as the "Barker's hypothesis" [23]. Barker suggested that nutritional conditions during fetal life can influence the metabolism and occurrence of disease during adult life. Fetal undernutrition in middle to late gestation can affect fetal growth, which may contribute to an increased risk of non-communicable diseases such as coronary heart disease in later life. Barker's hypothesis was then further extended to the developmental origins of health and disease (DOHaD) 
which emphasises the role of both the pre- and postnatal nutritional environment in determining adult diseases [24]. These three hypotheses suggests that early life nutritional environment can have lifetime consequences on later health. Hence, understanding the contribution of early nutrition, from pregnancy to early infancy is important to prevent the first manifestation of allergy or its progression, as well as early childhood malnutrition, which in turn lowers the risk of diseases in later life.

The prospective cohort study design of MICOS will generate a better understanding on the cause-effect relationship between early life nutrition and development of childhood malnutrition and allergy. In Malaysia, studies that examined the concept of early nutritional programming using a cohort study design are scarce. The USM Pregnancy Cohort Study was the first cohort study conducted in the state of Kelantan, Malaysia that linked maternal dietary exposures during pregnancy with birth outcomes in infants [68]. Another cohort study is being conducted in the state of Negeri Sembilan, Malaysia to determine early nutrition, growth and cognitive development of infants from birth to 2 years of age and is currently on-going [69]. Hence, the results of this study will fill the knowledge gap in this region by providing evidence for the role of early nutrition on growth and allergy development. In addition, the IgE blood test used in MICOS will help in identifying the prevalence of allergen sensitisation among infants in Malaysia. The incidence of allergic diseases and malnutrition that will be reported in the present study can enlighten the health professionals, policy makers as well as the public on the importance of early diagnosis of allergic diseases and malnutrition among infants. Through this study, we expect to contribute new knowledge and evidence of the association between early nutrition, childhood malnutrition and allergy which may be useful in helping health professionals and policy makers to develop dietary practice guidelines for pregnant women and infants to optimise the early life environment to ensure the health of future generations.

\begin{abstract}
Abbreviations
25(OH)D: 25 hydroxy-vitamin D; BMl: Body mass index; BSA: Body surface area; CLA: Chemiluminescent assay; FFQ: Food frequency questionnaire; GWG: Gestational weight gain; IgE: Immunoglobulin E; IOM: Institute of Medicine; ISAAC: International Study of Asthma and Allergies in Childhood; IYCF: Indicators for infant and young child feeding; JKEUPM: Ethics Committee for Research Involving Human Subjects, Universiti Putra Malaysia; LU: Net luminescence units; MANS: Malaysian Adult Nutrition Survey; MICOS: Mother and Infant Cohort Study; MREC: Medical Research and Ethics Committee; NHMS: National Health and Morbidity Survey; RNI: Recommended Nutrient Intakes for Malaysians; SEl: Sun exposure index; UK: United Kingdom; WHO: World Health Organization
\end{abstract}

\section{Funding}

This study was funded by the Ministry of Higher Education of Malaysia under the Fundamental Research Grant Scheme (Project's code: 04-01-15-1670FR).

\section{Authors' contributions}

YSC led the project, contributed to the design of the study, supervising the study, provided critical input, and drafting and finalizing the manuscript. FCW made contributions to the design and conduct of the study, drafting and finalizing the manuscript. IHI, YMC, GA, WYG, and AHAL were involved in the study design and provided critical input on the initial draft of the manuscript. MB will be involved in the analysis and interpretation of data. All authors reviewed and approved the manuscript for publication.

\section{Ethics approval and consent to participate}

The study was approved by the Ethics Committee for Research Involving Human Subjects, Universiti Putra Malaysia (JKEUPM) [Reference number: FPSK (FR16)P006] and the Medical Research and Ethics Committee (MREC), Ministry of Health Malaysia [Reference number: NMRR-16-1047-30,685]. Permission to conduct the study at the selected government health clinics was obtained from the State Health Department, District Health Office, medical officer of the selected government health clinics, and matron of the Maternal and Child Health Unit of the selected health clinics. Written informed consent for the respondents and their baby are obtained from the respondents prior to data collection.

\section{Consent for publication}

Not applicable.

\section{Competing interests}

The authors declare that they have no conflicts of interest.

\section{Publisher's Note}

Springer Nature remains neutral with regard to jurisdictional claims in published maps and institutional affiliations.

\section{Author details}

${ }^{1}$ Department of Nutrition and Dietetics, Faculty of Medicine and Health Sciences, Universiti Putra Malaysia, 43400 UPM Serdang, Selangor, Malaysia. ${ }^{2}$ Department of Paediatrics, Faculty of Medicine and Health Sciences, Universiti Putra Malaysia, 43400 UPM Serdang, Selangor, Malaysia. ${ }^{3}$ Malaysian Research Institute on Ageing, Universiti Putra Malaysia, 43400 UPM Serdang, Selangor, Malaysia. ${ }^{4}$ National Institute for Applied Statistics Research Australia, University of Wollongong, Northfields Ave, Wollongong, NSW 2522, Australia. ${ }^{5}$ Allergy \& Immunology Centre, Pantai Hospital Kuala Lumpur, 59100 Kuala Lumpur, Malaysia.

Received: 7 May 2018 Accepted: 9 July 2018

Published online: 18 July 2018

\section{References}

1. World Helth Organization. WHO global database on child growth and malnutrition. Geneva: WHO; 1997

2. Institute of Public Health National Health and Morbidity Survey 2015 (NHMS 2015). Vol II: Non-communicable diseases, risk factors \& other health problems. Putrajaya: Ministry of Health Malaysia; 2015.

3. Black RE, Allen LH, Bhutta ZA, Caulfield LE, de Onis M, Ezzati M, et al. Maternal and child undernutrition: global and regional exposures and health consequences. Lancet. 2008:371(9608):243-60.

4. Liu L, Johnson HL, Cousens S, Perin J, Scott S, Lawn JE, et al. Global, regional, and national causes of child mortality: an updated systematic analysis for 2010 with time trends since 2000. Lancet 2012;379(9832):21512161.

5. Casale D, Desmond C, Richter L. The association between stunting and psychosocial development among preschool children: a study using the south African birth to twenty cohort data. Child Care Health Dev. 2014;40: 900-10.

6. Caulfield LE, Richard SA, Rivera JA, Musgrove P, Black RE. Stunting, wasting, and micronutrient deficiency disorders. In: Jamison DT, Breman JG, Measham AR, Alleyne G, Claeson M, Evans DB, Jha P, Mills A, Musgrove P, editors. Disease control priorities in developing countries. Washington: World Bank; 2006. p. 551-67.

7. Sandjaja PBK, Rojroonwasinkul N, Le Nyugen BK, Budiman B, Ng LO, et al. Relationship between anthropometric indicators and cognitive performance in southeast Asian school-aged children. Br J Nutr. 2013;110(Suppl 3):S57-64.

8. Johansson SGO, Bieber T, Dahl R, Friedmann PS, Lanier BQ, Lockey RF, et al. Revised nomenclature for allergy for global use: report of the nomenclature 
review Committee of the World Allergy Organization, October 2003. J Allergy Clin Immunol 2004;113(5):832-836.

9. Yadav A, Naidu R. Clinical manifestation and sensitization of allergic children from Malaysia. Asia Pac Allergy. 2015;5:78-83.

10. Zheng T, Yu J, Oh MH, Zhu Z. The atopic march: progression from atopic dermatitis to allergic rhinitis and asthma. J Clin Cell Immunol. 2011;3(2):67-73.

11. Asher MI, Montefort S, Björkstén B, Lai CKW, Strachan DP, Weiland SK, et al. Worldwide time trends in the prevalence of symptoms of asthma, allergic rhinoconjunctivitis, and eczema in childhood: ISAAC phases one and three repeat multicountry cross-sectional surveys. Lancet. 2006;368(9537):733-43.

12. Palit A, Handa S, Bhalla AK, Kumar B. A mixed longitudinal study of physical growth in children with atopic dermatitis. Indian J Dermatol Venereol Leprol. 2007;73:171-5.

13. Ang SB, Cecilia TWC, Monika TP, Wee HL. Impact of atopic dermatitis on health-related quality of life among infants and children in Singapore: a pilot cross-sectional study. Proc Singapore Healthc. 2014;23(2):100-7.

14. Alvarenga TMM, Caldeira AP. Quality of life in pediatric patients with atopic dermatitis. J Pediatr. 2009;85(5):415-20.

15. World Health Organization: Children: reducing mortality. 2017 http://www. who.int/mediacentre/factsheets/fs178/en/. Accessed 22 Feb 2017.

16. Victora CG, Adaire L, Fall C, Hallal PC, Martorell R, Richter L, et al. Maternal and child undernutrition: consequences for adult health and human capital. Lancet. 2008;371(9609):340-57.

17. Bunyavanich S, Rifas-Shiman SL, Platts-Mills TA, Workman L, Sordillo JE, Camargo CA Jr, et al. Peanut, milk, and wheat intake during pregnancy is associated with reduced allergy and asthma in children. J Allergy Clin Immunol. 2014;133(5):1373-82.

18. Perkin MR, Logan K, Marrs T, Radulovic S, Craven J, Flohr C, et al. Enquiring about tolerance (EAT) study: feasibility of an early allergenic food introduction regimen. J Allergy Clin Immunol. 2016;137(5):1477-86.

19. Silvers KM, Frampton CM, Wickens K, Pattemore PK, Ingham T, Fishwick D, et al. Breastfeeding protects against current asthma up to 6 years of age. $J$ Pediatr. 2012;160(6):991-6.

20. van den Berg SW, Wijga AH, van Rossem L, Gehring U, Koppelman GH, Smit HA, et al. Maternal fish consumption during pregnancy and BMl in children from birth up to age 14 years: the PIAMA cohort study. Eur J Nutr. 2016:55(2):799-808.

21. Weisse K, Winkler S, Hirche F, Herberth G, Hinz D, Bauer M, et al. Maternal and newborn vitamin $D$ status and its impact on food allergy development in the German LINA cohort study. Allergy. 2013;68:220-8.

22. Woo JG, Guerrero ML, Ruiz-Palacios GM, Peng YM, Herbers PM, Yao W, et al. Specific infant feeding ractices do not consistently explain variation in anthropometry at age 1 year in urban United States, Mexico, and China cohorts. J Nutr. 2013;143(2):166-74.

23. Barker DJP. The fetal and infant origins of adult disease. BMJ. 1990; 301(6761):1111.

24. Gluckman P, Hanson M. Developmental origins of health and disease. Cambridge: Cambridge University Press; 2006

25. Guilloteau P, Zabielski R, Hammon HM, Metges CC. Adverse effects of nutritional programming during prenatal and early postnatal life, some aspects of regulation and potential prevention and treatments. J Physiol Pharmacol. 2009:60(3):17-35.

26. Lucas A. Programming by early nutrition in man. In: Bock GR, Chichester WJ, editors. The Childhood Environment and Adult Disease CIBA Foundation Symposium 156 Volume 156. United States: Wiley; 1991. p. 38-55.

27. Shapira N. Prenatal nutrition: a critical window of opportunity for mother and child. Womens Health. 2008;4(6):639-56.

28. Barker DJ, Gluckman PD, Godfrey KM, Harding JE, Owens JA, Robinson JS. Fetal nutrition and cardiovascular disease in adult life. Lancet. 1993; 341(8850):938-41.

29. Dewey KG. Reducing stunting by improving maternal, infant and young child nutrition in regions such as South Asia: evidence, challenges and opportunities. Matern Child Nutr. 2016;12(Suppl 1):27-38.

30. Black RE, Victora CG, Walker SP, Bhutta ZA, Christian P, de Onis M, et al. Maternal and child undernutrition and overweight in low-income and middle-income countries. Lancet. 2013;382(9890):427-51.

31. Institute of Medicine. Examining a developmental approach to childhood obesity: the fetal and early childhood years: workshop summary. Washington: The National Academies Press; 2015.

32. Edelbauer M, Loibichler C, Nentwich I, Gerstmayr M, Urbanek R, Szépfalusi Z. Maternally delivered nutritive allergens in cord blood and in placental tissue of term and preterm neonates. Clin Exp Allergy. 2004;34(2):189-93.
33. Jones CA, Holloway JA, Popplewell EJ, Diaper ND, Holloway JW, Vance GH, et al. Reduced soluble CD14 levels in amniotic fluid and breast milk are associated with the subsequent development of atopy, eczema, or both. J Allergy Clin Immunol. 2002;109(5):858-66.

34. Loibichler C, Pichler J, Gerstmayr M, Bohle B, Kisst H, Urbanek R, et al. Maternofetal passage of nutritive and inhalant allergens across placentas of term and pre-term deliveries perfused in vitro. Clin Exp Allergy. 2002;32(11):1546-51.

35. Jones CA, Holloway JA, Warner JO. Does atopic disease start in foetal life? Allergy. 2000;55(1):2-10.

36. Pastor-Vargas C, Maroto AS, Díaz-Perales A, Villaba M, Casillas Diaz N, Vivanco F, et al. Sensitive detection of major food allergens in breast milk: first gateway for allergenic contact during breastfeeding. Allergy. 2015;70(8): 1024-7.

37. Du Toit G, Roberts G, Sayre PH, Bahnson HT, Radulovic S, Santos AF, et al. Randomized trial of peanut consumption in infants at risk for peanut allergy. N Engl J Med. 2015;372:801-13.

38. Böttcher MF, Fredriksson J, Hellquist A, Jenmalm MC. Effects of breast milk from allergic and non-allergic mothers on mitogen- and allergen-induced cytokine production. Pediatr Allergy Immunol. 2003;14(1):27-34.

39. Böttcher MF, Jenmalm MC, Garofalo RP, Björkstén B. Cytokines in breast milk from allergic and nonallergic mothers. Pediatr Res. 2000;47(1):157-62.

40. Snijders BEP, Damoiseaux JGMC, Penders J, Kummeling I, Stelma FF, Van Ree $\mathrm{R}$, et al. Cytokines and soluble CD14 in breast milk in relation with atopic manifestations in mother and infant (KOALA study). Clin Exp Allergy. 2006;36(12):1609-15.

41. Lodge CJ, Tan DJ, Lau MX, Dai X, Tham R, Lowe AJ, et al. Breastfeeding and asthma and allergies: a systematic review and meta-analysis. Acta Paediatr. 2015;104(467):38-53.

42. Munblit D, Korsunskiy I, Asmanov A, Hanna H. The role of breastfeeding and weaning practices in allergic disease development. Curr Allergy Clin Immunol. 2017;30(2):76-81

43. Chin B, Chan ES, Goldman RD. Early exposure to food and food allergy in children. Can Fam Physician. 2014;60(4):338-9.

44. Lack G. Epidemiologic risks for food allergy. J Allergy Clin Immunol. 2008; 121(6):1331-6.

45. Hoxha M, Zoto M, Deda L, Vyshka G. Vitamin D and its role as a protective factor in allergy. Int Sch Res Notices. 2014;2014

46. Maslova E, Hansen S, Jensen CB, Thorne-Lyman AL, Strøm M, Olsen SF. Vitamin $D$ intake in mid-pregnancy and child allergic disease - a prospective study in 44,825 Danish mother-child pairs. BMC Pregnancy Childbirth. 2013; 13:199.

47. Miyake Y, Sasaki S, Tanaka K, Hirota Y. Dairy food, calcium and vitamin D intake in pregnancy, and wheeze and eczema in infants. Eur Respir J. 2010; 35:1228-34.

48. Best KP, Gold M, Kennedy D, Martin J, Makrides M. Omega-3 long-chain PUFA intake during pregnancy and allergic disease outcomes in the offspring: a systematic review and meta-analysis of observational studies and randomized controlled trials. Am J Clin Nutr. 2016;103(1):128-43.

49. Pele F, Bajeux E, Gendron H, Monfort C, Rouget F, Multigner L, et al. Maternal fish and shellfish consumption and wheeze, eczema and food allergy at age two: a prospective cohort study in Brittany, France. Environ Health. 2013;12(1):102.

50. Schlesselman JA. Sample size requirement in cohort and case-control studies of disease. Am J Epidemiol. 1974;99(6):381-4.

51. Kramer MS, McGill J, Matush L, Vanilovich I, Platt R, Bogdanovich N, et al. Effect of prolonged and exclusive breast feeding on risk of allergy and asthma: cluster randomised trial. BMJ. 2007;335:815.

52. Nurzalinda Z, Hamid Jan JM, Loy SL, Jake N, Harold DM, Abdullah M. Association of parental body mass index before pregnancy on infant growth and body composition: evidence from a pregnancy cohort study in Malaysia. Obes Res Clin Pract. 2016;10(Supplement 1):S35-47.

53. Institute of Medicine. Weight gain during pregnancy: reexamining the guidelines. Washington: National Academies Press; 2009.

54. Ministry of Health Malaysia. Malaysian Adult. Nutrition Survey 2003, vol. 2008. Putrajaya: Nutrition Section Family Health Development Division, Ministry of Health Malaysia.

55. Zaleha MI, Khadijah S, Noriklil Bukhary IB, Khor GL, Zaleha AM, Haslinda H, et al. Development and validation of a food frequency questionnaire for vitamin D intake among urban pregnant women in Malaysia. Malays J Nutr. 2015:21(2):179-90

56. Wessex Institute of Public Health University of Southampton. 1995. 
57. Institute of Medicine. Dietary reference intakes for calcium and vitamin D. Washington: National Academies Press; 2011.

58. Hall LM, Kimlin MG, Aronov PA, Hammock BD, Slusser JR, Woodhouse LR, et al. Vitamin $D$ intake needed to maintain target serum 25-hydroxyvitamin D concentrations in participants with low sun exposure and dark skin pigmentation is substantially higher than current recommendations. J Nutr. 2010;140:542-50.

59. Ellwood P, Asher M, Beasley R, Clayton T, Stewart A. The international study of asthma and allergies in childhood (ISAAC): phase three rationale and methods research methods. Int J Tuberc Lung Dis. 2005;9(1):10-6.

60. World Health Organization. Reference 2007 SPSS macro package. Geneva: WHO; 2007.

61. Institute of Public Health. Nutritional status (the third National Health and morbidity survey 2006). Malaysia: Ministry of Health; 2008.

62. World Health Organization. Indicators for assessing infant and young child feeding practices: part 2 measurement. Geneva: WHO; 2010.

63. Williams HC, Burney PGJ, Hay RJ, Archer CB, Shipley MJ, Hunter JJ, et al. The U.K. working Party's diagnostic criteria for atopic dermatitis. I. Derivation of a minimum set of discriminators for atopic dermatitis. Br J Dermatol 1994;131: 383-396.

64. Irei AV, Sato Y, Lin TL, Wang MF, Chan YC, Hung NTK, et al. Overweight is associated with allergy in school children of Taiwan and Vietnam but not Japan. J Med Investig. 2005;52:33-40.

65. Castro-Rodríguez JA, Holberg CJ, Wright AL, Martinez FD. A clinical index to define risk of asthma in young children with recurrent wheezing. Am J Respir Crit Care Med. 2000;162(4 Pt 1):1403-6.

66. Asher M, Keil U, Anderson H, Beasley R, Crane J, Martinez F, et al. International study of asthma and allergies in childhood (ISAAC): rationale and methods. Eur Respir J. 1995;8(3):483-91.

67. Strachan DP. Hay fever, hygiene, and household size. BMJ. 1989;299:1259-60.

68. Loy SL, Marhazlina M, Azwany YN, Hamid Jan JM. Higher intake of fruits and vegetables in pregnancy is associated with birth size. Southeast Asian J Trop Med Public Health. 2011;42(5):1214-23.

69. Nurliyana AR, Zalilah MS, Mohd Nasir MT, Gan WY, Tan KA. Early nutrition, growth and cognitive development of infants from birth to 2 years in Malaysia: a study protocol. BMC Pediatr. 2016;16:160.

Ready to submit your research? Choose BMC and benefit from:

- fast, convenient online submission

- thorough peer review by experienced researchers in your field

- rapid publication on acceptance

- support for research data, including large and complex data types

- gold Open Access which fosters wider collaboration and increased citations

- maximum visibility for your research: over $100 \mathrm{M}$ website views per year

At BMC, research is always in progress.

Learn more biomedcentral.com/submissions 